http://jmscr.igmpublication.org/home/ ISSN (e)-2347-176x ISSN (p) 2455-0450

crossref DOI: https://dx.doi.org/10.18535/jmscr/v7i12.98

\author{
Journal Of Medical Science And Clinical Research \\ IGM Publication \\ An Official Publication of IGM Publication
}

\title{
Types of refractive error in autistic children
}

\author{
Authors \\ Mariam M. B. Gebril ${ }^{1}$, Bahjah Abdulhamid Hamad Esehiyb ${ }^{2}$ \\ ${ }^{1}$ Assistant Professor, Ophthalmology, Benghazi University, Libya \\ ${ }^{2}$ Lecturer, Ophthalmology, Omar Almukhtar University, Libya
}

\begin{abstract}
Autism spectrum disorder is a neurodevelopmental disorder with a reported prevalence of 1.1 to $1.5 \%$ characterized by impairment of social interaction, communication, and/or repetitive behaviors or routines, The term autism spectrum disorder includes individuals with a diagnosis of autism and Asperger syndrome. In an effort to develop an improved understanding of autism spectrum disorder, many areas of visual processing have previously been investigated.

The aim of this study was to describe the refractive profile of a population of children with ASD.

Materials and Methods: Ophthalmic examination was carried out on children diagnosed with autism attending a pediatric eye clinic in Benghazi, Libya from October 2018 to April 2019.

Visual acuity was assessed by illiterate and child picture Snellen chart followed by complete eye examination and a Cycloplegic refraction was performed, Data were managed by SPSS version no. 20.00.

Results: a 26 child were included ranging from 3 to 15 years old, mean age (6.4 3.3 yr.) there were 14 boys $(53.8 \%)$ and 12 girls $(46.2 \%)$.

Refraction revealed 21 children had significant refractive errors with 11 children (42.3\%) had astigmatism, 10 children (38.5\%) had hypermetropia and 5 children (19.2\%) did not have a significant refractive error.

Conclusion: Significant refractive error mainly astigmatism was noted in the children with autism.

Correction and searching of these refractive errors early may enhance improvement of this disorder thus help them to have an agreeable life.
\end{abstract}

\section{Introduction}

Autism is one of an ascending public health concerns all over the world especially in the last two decades. Autism spectrum disorders (ASD) includes individuals with a diagnosis of autism and Asperger syndrome; they are a set of neurodevelopmental disorders characterized by impairment of socialization, communication, and behavior that usually begins in infancy or toddlerhood. ${ }^{(1)}$ Besides the difficulties in social communication which is the basis of the diagnostic criteria for autistic spectrum disorder
(ASD), there is growing evidence that individuals with ASD also experience atypical visual perception and demonstrate atypical visual exploratory behaviors (Mottron et al.). ${ }^{(2)}$

In Libya there is neither an adequate data about ASD's incidences nor their associated morbidity. However, in the UK, the reported prevalence of autism spectrum disorder is approximately $1.1 \%{ }^{(3)}$ whereas, in the United States the prevalence is reported to be $1.46 \%{ }^{(4)}$

Studies in Asia, Europe, and North America have identified individuals with ASD with an 
average prevalence between $1 \%$ and $2 \%$. About 1 in 59 children aged 8 years has been identified with autism spectrum disorder (ASD) and is reported to occur in all racial, ethnic, and socioeconomic groups ${ }^{(5)}$. So no one is immune.

So far, very limited number of reports can be found in the literature documenting the related eye morbidities in children with ASD at early ages, besides lack of skillful professionals which make the detection of detailed eye's risk factors as refractive error a difficult task. This is important because accurate accommodation is needed for effective near vision and normal ocular growth, and any deficits in vision will affect learning. ${ }^{(6)}$ Also undetected visual impairments are likely to affect quality of life, way of dealing of the surrounding information and therefore the behavior of individuals with autism. Awareness of sight loss and visual impairment should, therefore, be of concern to those providing care and support for people on the autism spectrum.

In an effort to develop an improved understanding of autism spectrum disorder. The aim of this study was to describe the refractive profile of a population of children with ASD.

\section{Materials and Methods}

Prior permission was brought from the parents and their attendances were asked all through the examination of the children.

Ophthalmic examination was carried out on children diagnosed with autism attending a pediatric eye clinic in Benghazi, Libya from October 2018 to April 2019. Children who could read and cooperate, Snellen's E-chart was used for assessing visual acuity uniocularlly and picture Snellen chart for how can't followed by a Cycloplegic refraction was performed by the use of $1 \%$ cyclopentolate and Topcon (KR-8800 auto kerato refractometer, Topcon corporation, Tokyo, Japan) auto refractmerte, A detailed fundus examination after dilatation was done by direct ophthalmoscope.

The final LogMAR score was determined; 0.0 is equivalent to 6l6 Snellen acuity (average acuity).
Spectacle prescription was given to all children with refractive errors when needed.

For the purpose of this study, significant refractive error was considered as follows Hypermetropia $\geq$ $+1.50 \mathrm{DS}$,

Myopia $>-1.00$ DS, Astigmatism $\geq \pm 1.00$ DC.

Data were managed by spss no 20 .

\section{Results}

Twenty six children were included ranging from 3 to 15 years old, mean age $(6.4 \pm 3.3 \mathrm{yr}$.) there were 14 boys $(53.8 \%)$ and 12 girls (46.2\%).

With male to female ratio of 1.2:1. (Figure 1)

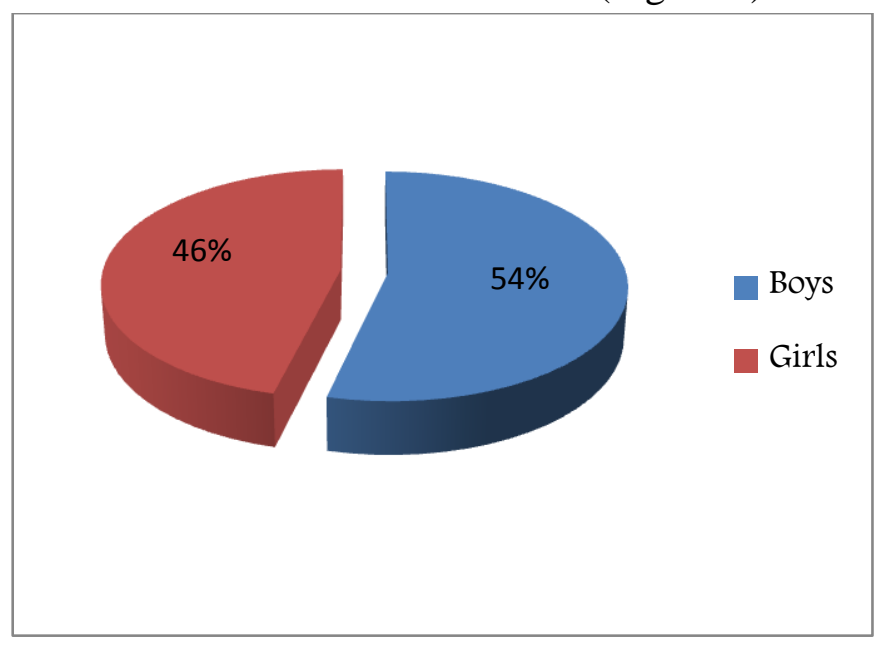

Figure1: Gender distribution

Five of them had esotropia which contributing of $19 \%$ of the children, anisometropia in $28.6 \%$ Astigmatism bilateral in $92 \%$, unilateral in $8 \%$.

Abnormal distant visual acuity (VA) (logmar 0.11) was seen in 6 children (23\%), normal distant VA (logmar 0) in 6 children $(23 \%)$ and 14 children $(54 \%)$ did not cooperate for vision testing Figure (2) shows the distribution of distant acuity.

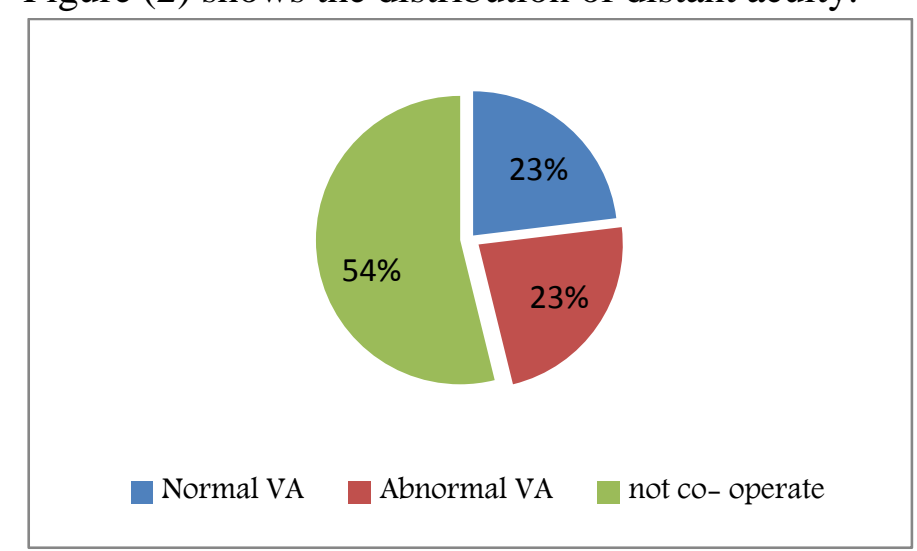

Figure 2: Distribution of distant visual acuity 
All the children co-operated for cycloplegic refraction.

21 children $(81 \%)$ had significant refractive error by definition of the study: 12 children revealed astigmatism (46\%), 8 children had hypermetropia ranging from 1D to $4 \mathrm{D}$ was observed in $(30 \%), 1$ child had a low degree myopia -1.50D (3.8\%) and 5 (19\%) children did not had a significant refractive error (figures 3,4).

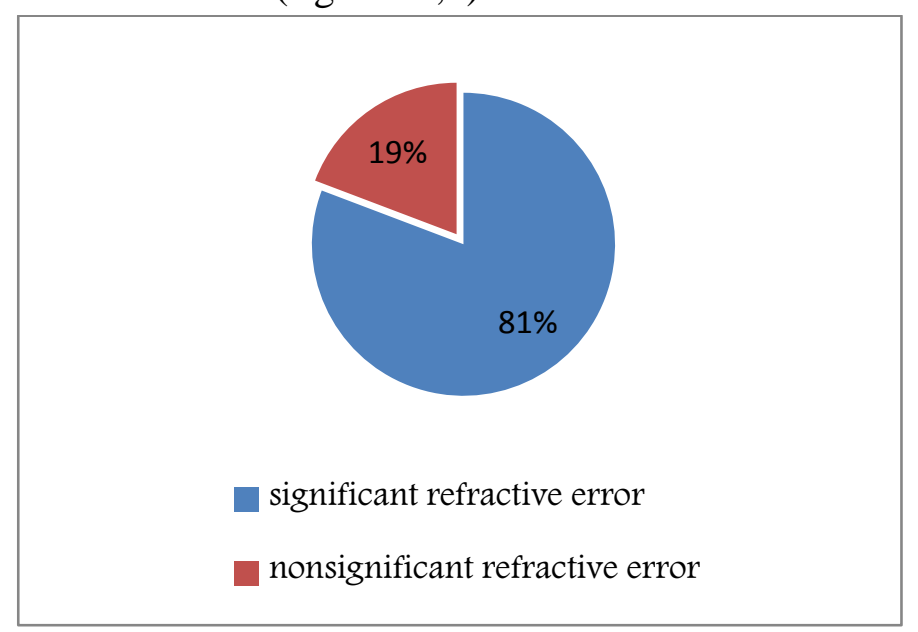

Figure 3: Distribution of refractive error.

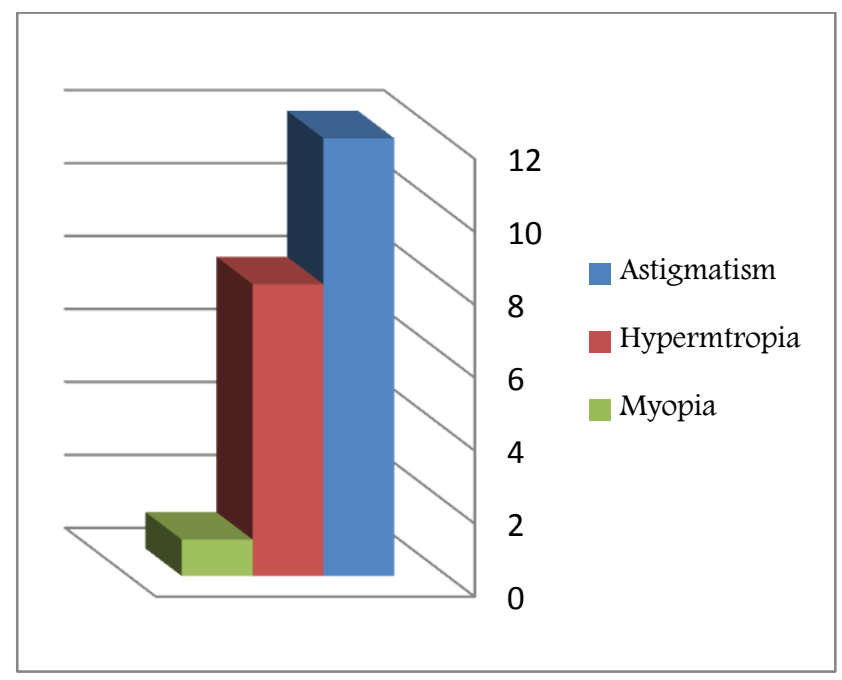

Figure 4: Types of refractive error distribution.

Astigmatism was the most common type of refractive error observed. Compound hypermetropic astigmatism (50\%) was the commonest type of astigmatism noted.

Table 1 shows the distribution of astigmatism. Simple hypermetropic and simple myopic astigmatism were not observed in any of the eyes.
Table 1: Distribution of Astigmatism

\begin{tabular}{|l|c|}
\hline Types of astigmatism & Percentage \\
\hline Compound hypermetropic astigmatism & $50 \%$ \\
\hline Mixed astigmatism & $35.7 \%$ \\
\hline Compound myopic astigmatism & $14.3 \%$ \\
\hline Simple hypermetropic astigmatism & $0 \%$ \\
\hline Simple myopic astigmatism & $0 \%$ \\
\hline
\end{tabular}

\section{Discussion}

Over all the significant refractive error in our study was $81 \%$, this high percentage could be contributed to the fact that they were referred patients that came for screening to our clinic.

Astigmatism was the major refractive error in our series of $46 \%$ followed by $30 \%$ of hypermetropia. This is close to the findings of Denis et al. ${ }^{(7)}$ and Ikeda et al. ${ }^{(3)}$ in their studies they observed that significant refractive error in a larger number of autistic children had unilateral ,bilateral astigmatism, strabismus in children with autism. $19 \%$ of our patients had strabismus similar to Davitt et al who found it to be $(21 \%)$ patients had strabismus ${ }^{(8)}$. Trachtman et al. came about that people with autism tend to have abnormal electroretinograms, deficient evoked visual potentials, and atypical opticokinetic nystagmus, they also have a higher than expected incidence of strabismus sand oculomotor deficiencies, refractive error. ${ }^{(9)}$ Milne et al. studied several vision aspects, including VA. On average they reported considerably poorer results in both eyes in the ASD group compared with the typically developing group. ${ }^{(10)}$

This is a lower estimate of visual disturbance in the ASD group than that reported by Denis et al. However, the incidence was higher than in the typical population, whereas the incidences of hypermetropia, astigmatism and strabismus are approximately 3-4\% (Gronlund et al. 2006), 5.48.6\% (Hirsch 1963; Zadnik et al. 1992) and 2-5\% (Graham 1974; Stayte et al. 1993), respectively. ${ }^{(11-}$ 15)

Hypermyopia is linked with depressed visuocognitive ability, reading ability, and visual attention in young children. ${ }^{(16)}$

In our study the boys: girls ratio is $1.2: 1$ with a slight prodomince of males which is in contrary to 
many searches which say that about 4 times more common in boys than among girls ${ }^{(5)}$ However, it may be noted that current research relating to possible sex differences in the autism phenotype suggests that females with autism may beunder- or mis-diagnosed and that the sex ratio of males and females diagnosed with autism may change over time. ${ }^{(17,18)}$

Our study is limited by the small number of participants. Also the short duration of the study. Visual acuity could be assisted in only $45 \%$; due to unfamiliarity of the child to the place, working staff or the test itself. There were no data available regarding prevalence of autism in Benghazi, neither data on number and types of ocular finding in them.

\section{Conclusion}

In conclusion, astigmatism was noted in the children with autism to be the main refractive error.

We recommend a comprehensive eye examination by a pediatric ophthalmologist, optimally asa part of a multidisciplinary clinic, for all children diagnosed with autism and related disorders. And plan to work in the same environment of those children to gain their cooperation and thrust, so more knowledge could be gained regarding this disorder. Correction and searching of these refractive errors early may enhance improvement of this disorder thus help them to have an agreeable life

This study is limited by a small sample size, and further studies with more patients and including a full clinical case-history analysis are required.

\section{References}

1. Barbaro, J., \& Dissanayake, C. (2009). Autism spectrum disorders in infancy and toddlerhood: A review of the evidence on early signs, early identification tools, and early diagnosis. Journal of Developmental and Behavioral Pediatrics, 30(5), 447-459. https://doi.org/10.1097/DBP.0b013e3181b a0f9f.
2. Mottron, L., Dawson, M., Soulieres, I., Hubert, B., \&Burack, J. A. _ (2006). Enhanced perceptual functioning in autism: An Update and eight principles of autistic perception. Journal of Autism and Developmental Disorders, 36, 27-43. https://doi:10.1007/s10803-005-0040-7.

3. Bailey A, Luthert P, Dean A, et al. A Clinicopathological Study of Autism. Brain 1998;121:889-905.

4. Christensen DL, Baio J, Van Naarden Braun K, et al. Prevalence and Characteristics of Autism Spectrum Disorder among Children Aged 8 YearsAutism and Developmental Disabilities Monitoring Network, 11 Sites, United States, 2012. MMWR Surveil Summ 2016;165:1-23.

5. Centers for Disease Control and Prevention. (2010). Autism spectrum disorder: Data and statistics. Retrieved April 28, 2011, from http://www.cdc.gov/ncbddd/autism/data.ht $\mathrm{ml}$.

6. VIP-HIP Study Group. Kulp MT, Ciner E, Maguire M, et al. Uncorrected Hyperopia and Preschool Early Literacy: Results of the Vision in Preschoolers-Hyperopia in Preschoolers (VIP-HIP) Study. Ophthalmology 2016; 123:681-9.

7. Denis $\mathrm{D}$, Burillon $\mathrm{C}$, Livet $\mathrm{MO}$, Burguière O. Ophthalmologic signs in children with autism. J Fr Ophtalmol1997;20:103-10.

8. Davitt BV, Cruz OA, Ikeda J, et al. Brief report: incidence of ophthalmologic disorders in children with autism. J Autism Dev Disord2012;42:1-5.

9. Trachtman JN. Background and history of autism in relation to vision care. Optometry 2008;79:391-6.

10. Milne E, Griffiths H, Buckley D, Scope A. Vision in children and adolescents with autistic spectrum disorder: evidence for reduced convergence. J Autism Dev Disord 2009;39:965-75. 
11. Gronlund, M. A., Andersson, S., Aring, E., Hard, A. L., \& Hellstrom, A. (2006). Ophthalmological findings in a sample of Swedish children aged 4-15 years. Acta Ophthalmologica Scandinavica, 84, 169176. https://doi:10.1111/j.16000420.2005.00615.x.

12. Hirsch, M. J. (1963). Changes in astigmatism during the first eight years of school-an interim report from the Ojai Longitudinal study. American Journal of Optometry, 40, 127-132.

13. Zadnik, K., Mutti, D. O., \& Adams, A. J. (1992). Astigmatism in children: What's the rule? Ophthalmic and Visual Optics Technical Digest, 3, 68-71.

14. Graham, P. A. (1974). The epidemiology of strabismus. The British Journal of Ophthalmology, 58, 224-231. https://doi:10.1136/bjo.58.3.224.

15. Stayte, M., Reeves, B., \& Wortham, C. (1993). Ocular and vision defects in preschool children. The British Journal of Ophthalmology, 77, 228-232. https://doi:10.1136/bjo.77.4.228.

16. Kulp, M. T., Ciner, E., Maguire, M., Moore, B., Pentimonti, J., Pistilli, M., ... Ying, G. (2016). Uncorrected Hyperopia and Preschool Early Literacy. Ophthalmology, 123(4), 681-689. https://doi:10.1016/j.ophtha.2015.11.023

17. Lai, M. C., Lombardo, M. V., \& Auyeung, B. (2015). Sex/gender differencesand autism: setting the scene for future research. Journal of theAmerican Academy of Child and Adolescent Psychiatry, 54, 11-24.
18. Van Wijngaarden-Cremers, P. J., Van Eeten, E., Groen, W. B., Van D eurzen, P. A., Oosterling, I. J., \& Van der Gaag, R. J. (2014).Gender and age differences in the core triad of impairments in autism spectrum disorders: a systematic review and meta-analysis. Journal of Autism and Developmental Disorders, 44(3), 627-635. 